\title{
The Fuzzy Connection between SARS-CoV-2 Infection and Loss of Renal Function
}

\author{
L.V.K.S. Bhaskar ${ }^{\mathrm{a}}$ Bijan Roshan $^{\mathrm{b}}$ Hamid Nasri $^{\mathrm{c}}$ \\ aDepartment of Zoology, Guru Ghasidas Vishwavidyalaya, Bilaspur, India; 'bivision of Nephrology, Scripps Clinic, \\ La Jolla, La Jolla, CA, USA; 'Department of Nephropathology, Nickan Research Institute, Isfahan, Iran
}

Dear Editor,

We appreciate the highly time-appropriate information presented in the article "Coronavirus Disease 19 Infection Does Not Result in Acute Kidney Injury: An Analysis of 116 Hospitalized Patients from Wuhan, China" by Wang et al. [1]. COVID-19 (coronavirus disease) is a newly emerged pandemic caused by a novel severe acute respiratory syndrome coronavirus 2 (SARS-CoV-2). As a close relative of other epidemic coronaviruses (SARS and Middle East Respiratory Syndrome), SARS-CoV-2 is highly contagious and exhibits flu-like symptoms with pneumonic illness [1]. Although $85 \%$ of patients recover from infection without needing hospitalization, elderly people and people with another condition that compromises the immune system such as hypertension or diabetes appear to develop serious illness [1,2]. Detection of viral RNA in urine and kidney tissue of SARS-CoV-2-infected patients indicates the kidney as a target of infection [2]. Several of the recent reviews have mentioned kidney manifestations of COVID-19 [3, 4]. While angiotensinconverting enzyme 2 (ACE2) receptors are the functional receptor for the SARS coronavirus, their presentation in the lower respiratory tract, kidney, duodenum, and small intestine might provide possible routes of entry for the SARS-CoV [5]. Studies in a mouse model of SARS-CoV infection demonstrated that ACE2 expression is vital for viral entry and ACE2 overexpression is directly proportional to disease severity [6]. As bradykinin B1 receptor mediates the cross talk between ACE2 and the kinin-kallikrein system in setting the inflammation, selective bradykinin B1 receptor blockers could be used as a promising agent to prevent tissue inflammation during $\mathrm{CO}$ VID-19 infection [7].

Significant functional impairment of the kidney in COVID-19 patients $[8,9]$ is well known, and we see that in our patients frequently. Development of acute kidney injury (AKI) is also associated with significant increased mortality during hospital stay [9]. AKI can be a surrogate for multi-organ failure and serves as a negative prognostic factor for survival in COVID-19 patients [10].

We wonder whether the incidence of AKI by reporting time, and not the total incidence of AKI, was reported in this study by Wang et al. [1] They report that as of February $13,2020,7(6.03 \%)$ acute respiratory distress syndrome patients transferred to ICU died of respiratory failure. This is much lower than the overall mortality of more than $52 \%$ reported for acute respiratory distress syndrome in COVID-19 patients from Wuhan [10]. We suspect the same methodologic problem underlies the underestimation of AKI in COVID-19 in his study. Therefore, larger studies in this regard are necessary.

\section{KARGER}

(c) 2020 S. Karger AG, Basel 


\section{Disclosure Statement}

The authors report no conflict of interests.

\section{Author Contributions}

Primary draft by L.V.K.S.B. B.R. edited the paper. H.N. conducted further edits. All authors read and signed the final paper.

\section{Funding Sources}

There was no financial support.

\section{References}

1 Wang L, Li X, Chen H, Yan S, Li D, Li Y, et al. Coronavirus disease 19 infection does not result in acute kidney injury: an analysis of 116 hospitalized patients from wuhan, China. Am J Nephrol. 2020;51(5):343-8.

2 Naicker S, Yang CW, Hwang SJ, Liu BC, Chen JH, Jha V. The novel coronavirus 2019 epidemic and kidneys. Kidney Int. 2020;97(5): 824-8.

3 Valizadeh R, Baradaran A, Mirzazadeh A, Bhaskar L. Coronavirus-nephropathy; renal involvement in COVID-19. J Renal Inj Prev. 2020;9(2):e18. .

4 Hamidian Jahromi A, Mazloom S, Ballard DH. What the European and American health care systems can learn from China COVID-19 epidemic; action planning using pur- pose designed medical telecommunication, courier services, home-based quarantine, and COVID-19 walk-in centers. Immunopathol Persa. 2020;6(2):e17.

5 Hamming I, Timens W, Bulthuis ML, Lely AT, Navis G, van Goor H. Tissue distribution of ACE2 protein, the functional receptor for SARS coronavirus. A first step in understanding SARS pathogenesis. J Pathol. 2004;203(2): 631-7.

6 Yang XH, Deng W, Tong Z, Liu YX, Zhang $\mathrm{LF}, \mathrm{Zhu} \mathrm{H}$, et al. Mice transgenic for human angiotensin-converting enzyme 2 provide a model for SARS coronavirus infection. Comp Med. 2007;57(5):450-9.

7 Tolouian R, Zununi Vahed S, Ghiyasvand S, Tolouian A, Ardalan M. COVID-19 interac- tions with angiotensin-converting enzyme 2 (ACE2) and the kinin system; looking at a potential treatment. J Renal Inj Prev. 2020;9(2): e19. .

8 Cheng Y, Luo R, Wang K, Zhang M, Wang Z, Dong $\mathrm{L}$, et al. Kidney disease is associated with in-hospital death of patients with COVID-19. Kidney Int. 2020;97(5):829-38.

9 Yin W, Zhang P. Infectious pathways of SARS-CoV-2 in renal tissue. J Nephropathol. 2020;9(4):e37. http://dx.doi.org/10.34172/ jnp.2020.37.

10 Wu C, Chen X, Cai Y, Xia J, Zhou X, Xu S, et al. Risk factors associated with acute respiratory distress syndrome and death in patients with coronavirus disease 2019 pneumonia in $\mathrm{Wu}$ han, China. JAMA Intern Med. 2020 Mar 13. 